\title{
Endgame for polio eradication? Options for overcoming social and political factors in the progress to eradicating polio.
}

\author{
Pavan Ganapathiraju \\ Thomas Jefferson University \\ Christiaan B Morssink \\ University of Pennsylvania \\ James D. Plumb \\ Thomas Jefferson University
}

\section{Follow this and additional works at: https://jdc.jefferson.edu/healthpolicyfaculty \\ Part of the Public Health Commons \\ Let us know how access to this document benefits you}

\section{Recommended Citation}

Ganapathiraju, Pavan; Morssink, Christiaan B; and Plumb, James D., "Endgame for polio eradication? Options for overcoming social and political factors in the progress to eradicating polio." (2015). College of Population Health Faculty Papers. Paper 74.

https://jdc.jefferson.edu/healthpolicyfaculty/74

This Article is brought to you for free and open access by the Jefferson Digital Commons. The Jefferson Digital Commons is a service of Thomas Jefferson University's Center for Teaching and Learning (CTL). The Commons is a showcase for Jefferson books and journals, peer-reviewed scholarly publications, unique historical collections from the University archives, and teaching tools. The Jefferson Digital Commons allows researchers and interested readers anywhere in the world to learn about and keep up to date with Jefferson scholarship. This article has been accepted for inclusion in College of Population Health Faculty Papers by an authorized administrator of the Jefferson Digital Commons. For more information, please contact: JeffersonDigitalCommons@jefferson.edu. 


\title{
Endgame for polio eradication? Options for overcoming social and political factors in the progress to eradicating polio
}

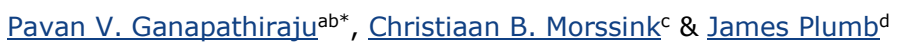

\begin{abstract}
In 1988, the Global Polio Eradication Initiative (GPEI) was launched with the goal of eradicating polio by the year 2000. After 25 years, several dynamics still challenge this large public health campaign with new cases of polio being reported annually. We examine the roots of this initiative to eradicate polio, its scope, the successes and setbacks during the last 25 years and reflect on the current state of affairs. We examine the social and political factors that are barriers to polio eradication. Options are discussed for solving the current impasse of polio eradication: using force, respecting individual freedoms and gaining support from those vulnerable to fundamentalist 'propaganda'. The travails of the GPEI indicate the need for expanding the Convention on the Rights of the Child to address situations of war and civic strife. Such a cultural and structural reference will provide the basis for global stakeholders to engage belligerent local actors whose local political conflicts are barriers to the eradication of polio. Disregard for these actors will result in stagnation of polio eradication policy, delaying eradication beyond 2018 .
\end{abstract}

\section{Introduction}

Polio is an acute viral disease of the picornavirus family that can damage the digestive tract and the nervous system, leading to flaccid paralysis (Osazuwa-Peters, 2011). Polio has distinctive characteristics that establish its importance in global health. First, it is a disease that principally affects children under five years of age (Osazuwa-Peters, 2011). Second, polio infection is very acute and spreads rapidly via faecal-oral route which often leads to devastating paralysis resulting in handicap victims and reducing quality of life, and even death in some cases (Osazuwa-Peters, 2011). Polio has no known cure but can be prevented by vaccination.

Before Jonas Salk invented the polio vaccine in 1955, polio paralysed and killed up to 500,000 people annually worldwide (CCP, 2013). Salk's inactivated polio vaccine (IPV) reduced polio transmission in the USA from 20,000 cases per year in the 1950 s to around 1000 cases by the 1960 s (CCP, 2013). In 1961, oral polio vaccine (OPV) was invented by Albert Sabin, and from 1963, the USA replaced IPV with OPV in mass polio vaccination campaigns (CCP, 2013; Gautam, 2005). After the Centers for Disease Control and Prevention (CDC) concluded that the transmission of polio had ended in the USA in 1979, Rotary International committed to provide vaccines to six million children in the Philippines (GPEI, 2014). Due to this successful campaign and followed by campaigns in other countries, Rotary collaborated with Albert Sabin on a plan to vaccinate all children against polio worldwide utilising Sabin's OPV. The Rotary PolioPlus programme was launched in 1985 (CCP, 2013; Gautam, 2005; GPEI, 2014).

In spite of the efforts of PolioPlus, the forty-first World Health Assembly (WHA) ratified a resolution for the worldwide eradication of polio, realising that polio was still endemic in developing countries (Gautam, 2005). In 1988, the Global Polio Eradication Initiative (GPEI) was launched with the goal of eradicating polio by the year 2000. When this goal was not achieved, a five-year extension was enacted. Polio worldwide has decreased from an estimated 350,000 cases in 1988 to just 416 cases in 2013 
(CDC, 2014b; GPEI, 2014). However, without complete eradication, polio continues to plague populations and to burden the public health system of all infected countries (Lahariya, 2007; WHO, 2012). We review the current state of affairs of the ambitious initiative to eradicate polio and examine factors contributing as barriers to polio eradication, which impede eradication goals, potential policy solutions and recommendations. Three options are discussed for solving the current impasse of total polio eradication.

\section{Situational analysis}

According to the GPEl's surveillance data from 25 June 2014, 106 cases were reported in 2014. In addition to the three endemic countries (Nigeria, Afghanistan and Pakistan), cases in 2014 were also reported in Cameroon, Equatorial Guinea, Ethiopia, Iraq and Syria (CDC, 2014b; GPEI, 2014). On 5 May 2014, World Health Organization (WHO) declared the recent international transmission of wild polio strains as a public health emergency and issued temporary recommendations under the International Health Regulations (IHR) of 2005 to prevent further spread of polio (CDC, 2014b).

Strategies for worldwide vaccination have tremendously improved over the last few years. In terms of routine vaccination, worldwide coverage of infants by age 12 months with three doses of OPV via routine vaccinations was estimated at $84 \%$ (CDC,2014a). The persistence of wild polio transmission in restricted areas has made it very difficult to eradicate. Studies demonstrate a correlation between the attack rate for cases of polio and the percentages of children younger than five years of age who had received at least three doses of OPV (Nathanson \& Kew, 2010). Polio circulates with high frequency causing infantile paralysis in infants aged 6-12 months. Most paralytic cases of polio occur in infants older than 12 months of age, urging the need for vaccination between ages 6 and 12 months (Nathanson \& Kew, 2010). In 2013, 265 supplementary immunisation activities (SIAs) using OPV were administered in 42 countries which included 113 immunisation days, 134 sub-national immunisations, 13 child days and five largescale mop-up campaigns (CDC, 2014a).

In Africa, Nigeria is the only country that still has circulation of the wild strain of polio. Since 2003, Nigeria has been a basin for reintroducing wild polio strains in 25 polio-free countries (CDC, 2013a, 2013b). In 2013, 53 cases were reported in 30 districts, a reduction from the 122 reported cases in 60 districts in 2012 (CDC, 2014a). In 2013, SIAs were postponed temporarily in some armed conflict areas in northeastern Nigeria (CDC, 2014a). During January-April 2014, Nigeria reported 3 cases total, and as of May 2014, Nigeria has reported a total of 4 cases for 2014 (GPEI, 2014). Despite setbacks in 2013, Nigeria has seen remarkable progress towards polio eradication, and successful interruption of transmission will depend on a sustained focus on the issues causing setbacks and an effective outbreak response (CDC, 2013a, 2013b).

While much of the world is concerned with the wild polio strain, circulating vaccine-derived poliovirus (cVDPV) outbreaks is a major issue in the three endemic countries in addition to the wild strain. The cVDPV is a genetically unstable Sabin Strain that mutates back to the parent strain as it circulates for long periods of time in populations with low herd immunity (Modlin,2010). Outbreaks of cVDPV were first identified in 2000 during an investigation of 21 cases in Hispaniola. The importance today is attributed to outbreaks that have occurred in incomplete immunisation campaigns, where less than $50 \%$ of children receive all three doses of OPV. Even after the wild strain is completely eradicated, the possibility of cVDPV exists for additional years, reintroducing the wild strain back into the population (Modlin, 2010; 
Nathanson \& Kew, 2010). Currently, cVDPV is detected via surveillance for acute flaccid paralysis cases and stool specimens at accredited laboratories of the Global Polio Laboratory Network (CDC, 2014a).

In Afghanistan, polio transmission is now concentrated in conflict-affected regions of Helmand, Kandahar and Urozgan. In 2013, a total of 14 cases were reported in 10 districts, a decrease from reported cases in 21 districts in 2012. This marks the lowest number of reported cases of the wild strain in polio in Afghanistan since 2004 (CDC, 2014a). Furthermore, in 2013, only 1 case was reported from the Helmand Province in southern Afghanistan. As of May 2014, Afghanistan has only reported a total of 6 cases of polio (GPEI, 2014). During 2010-2012, the conflict in Afghanistan hindered vaccinators from safely accessing children in the southern area of Afghanistan (CDC, 2014a). However, negotiations greatly improved access to children in 2013 along with the efforts to improve the quality of SIAs, but the aim of total global polio eradication is being tested by limitations in access and insecurity within other countries (CDC, 2014a).

As of 2013, out of 152 districts in Pakistan, transmission is persistent in 23, an increase since 2012 (CDC, 2014a). In 2013, SIAs were suspended temporarily in some areas of Pakistan due to risks of violence. In Pakistan, targeted attacks against polio vaccinators and law enforcement assigned to protect vaccinators have compromised the implementation of SIAs in parts of tribal areas (CDC, 2014a). The sustained ban on polio vaccination in North and South Waziristan, tribal areas where the local leaders have prevented vaccination of children since June 2012, is principally responsible for the increase in the wild polio strain cases in 2013-2014 and for recent importation into Afghanistan and Syria (CDC, 2014a). Eliminating polio from the sub-districts has been a complicated issue due to re-emergence in other poliofree areas. Afghanistan and Pakistan together consist of a single 'epidemiologic block' due to crossborder transmission with population movements between the two countries (Nathanson \& Kew, 2010; WHO, 2010). All but 1 case in 2013 and all cases in 2014 in eastern Afghanistan were linked to the wild strain of polio importation from Pakistan.

The number of polio outbreaks after importation of the wild strain into previously polio-free countries has increased from 6 cases (Chad and Niger) in 2012 to 256 cases in five countries in 2013 (CDC, 2014a). Importation of the wild strain of polio from Nigeria into other parts of Africa resulted in 217 cases in 2013 including 9 in Ethiopia, 14 in Kenya and 194 in Somalia; one outbreak was reported in Ethiopia in 2014 (CDC, 2014a). Importation from Pakistan to Syria resulted in 35 cases in 2013 and 1 case in 2014. Four cases were reported in Cameroon and three in 2014, and 3 cases were reported in Equatorial Guinea in early 2014 (CDC, 2014a).

Despite the increases in cases since 2012, 2014 marked the three-year anniversary since a case has reappeared in India, removing itself officially from one of the four remaining endemic countries in 2012 (CDC, 2014b). However, uninterrupted transmission continues in three endemic countries and reestablished countries. Even with the goal of total eradication as a high priority, we examine two factors that are contributing as barriers to achieve this goal.

\section{Social factors}

A human rights approach to health supports giving priority to improving health and reducing inequalities (Marmot, 2014). Achieving these goals requires absolute action on the social factors of health as a major policy challenge (Marmot, 2014). The principal social factor in polio eradication is inadequate flexibility in 
accessing children safely (Toole, Simmonds, Coghlan, \& Mojadidi, 2009). The bridge between low socioeconomic status and limited access to vaccination can be explained in two ways.

First, the population of interest do not utilise available resources (Cakouros, 2012). While awareness of polio vaccination is widespread, many people in affected communities do not perceive vaccination to be a high priority. Community-based surveys were conducted in 2008 throughout Afghanistan and found that, while most parents knew about the polio campaigns, very few were aware that multiple doses of OPV were required or that OPV prevented paralysis (Toole et al.,2009). Even fewer respondents were able to identify paralysis as a sign of polio infection or were aware that there was no treatment (Toole et al., 2009). Community leaders are not educated nor mobilised to get more invested in polio vaccination (Toole et al., 2009). Community development that incorporates strategies for community empowerment as well as social change is a key factor for the development of a healthy population (Aday, 2005). Furthermore, the cultural values of the three endemic nations are essentially shaped by religion (Osazuwa-Peters, 2011). For example, the northern part of Nigeria is predominantly Muslim with the Supreme Council of Islamic Affairs having control of the population for whom religion is a way of life (Osazuwa-Peters, 2011). With such belief among locals in Nigeria, polio, named Shan Inna, is thought to be caused by evil spirits who drink blood of victims resulting in paralysis or death (OsazuwaPeters, 2011). Also, many people in rural areas believe in native medicine and health, and often opt for 'traditional doctors' for health care as opposed to vaccination (Osazuwa-Peters, 2011).

Second, immunisation locations do not offer sufficient vaccines to supply the demand of the population (Cakouros, 2012). Many of the people in the three endemic nations live in rural areas, and medical care for them is in the form of primary health care (Osazuwa-Peters, 2011). However, the primary health care system may not always be up to expected standards in delivery of vaccination. For example, the primary health care system in Nigeria has been in a state of decay for many years and is presently in poor infrastructural shape (Osazuwa-Peters, 2011). Therefore, issues such as vaccine storage in rural areas can be a major challenge not only in Nigeria but also in Afghanistan and Pakistan (OsazuwaPeters, 2011).

However, much effort has been made in recent years in social mobilisation. In 2008, UNICEF launched an initiative in Jalalabad, Afghanistan, to engage women literacy students in polio eradication (UNICEF, 2012). This initiative allowed women to become an important part of the polio eradication programme in the WHO Eastern Region and gradually move up into various leadership positions (UNICEF, 2012). Due to the success in Jalalabad, the GPEl attempted to model this structure to implement a similar programme in southern Afghanistan. The GPEI had major success with the programme in 2012 with a recruitment of 75 literacy students oriented to the polio eradication programme and recruited as social mobilisers (UNICEF,2012). Since 2012, many female vaccinators and female supervisors have been hired for polio eradication in southern Afghanistan (UNICEF, 2012).

\section{Political factors}

Recent deadly attacks on polio vaccinators in politically fragile areas of Pakistan and Nigeria are posing a serious threat to GPEI. As experts working in polio endemic nations, which are largely Muslim, the increasing militancy, political unrest and deteriorating security conditions are common factors that threaten polio eradication in all three endemic nations (Abimbola, Malik, \& Mansoor, 2013). However, the 
central causes of failure of polio eradication differ among the three endemic nations and are entrenched in country-specific characteristics.

Security issues pose a serious barrier to achieving high polio vaccination coverage in Afghanistan (Toole et al., 2009). President Karzai has proposed to bring an end to the Afghan war via a political settlement with the Taliban (Toole et al., 2009; Trofimov, 2010). However, Taliban leadership has repeatedly rejected negotiations as long as US and foreign troops remain in the country (Trofimov, 2010). Political endorsement of polio eradication programmes may no longer be appropriate. In security-compromised areas run by the Taliban, these endorsements are having a negative effect (Toole et al., 2009; Trofimov,2010). Since late 2012, the Taliban permitted vaccination again in Afghanistan and near the Pakistan border after President Karzai repeatedly insisted the Taliban and other insurgents allow vaccination teams to enter security-compromised areas as long as there was no government involvement (Babakarkhail \& Nelson, 2013; Popalzai, 2012). However, even with the many efforts to resolve these issues, controversy continues. The Taliban continues to be the source of blame for continued violent activities.

When the Taliban in Afghanistan was in power from 1995 to 2001, it fully supported the GPEl, and other combatant groups such as Al Qaeda were not interested in interrupting national polio eradication efforts (Abimbola et al., 2013). The recent attacks against polio workers in Pakistan and Nigeria may not be repeated in Afghanistan because of the re-emergence of the Taliban and the group's ambition to regain its control of Afghan national politics (Abimbola et al., 2013). Taliban are now working on rebuilding trust among the population and have allowed locals to engage in social campaigns, including the GPEI (Abimbola et al., 2013). The situation is a fragile one; however, Taliban-like or pro-Al Qaeda forces entering Afghanistan from other parts may deter the GPEI by interfering with polio eradication efforts as part of a political strategy tool for countering the western front in Afghanistan (Abimbola et al., 2013).

In Pakistan, polio vaccinators have been performing the same procedures without interference for the last 15 years (Abimbola et al., 2013). Until recently, national immunisation days were considered part of routine health activity for the country. But, in the past two years, polio vaccination workers have been attacked in tribal areas and other parts of Pakistan (Abimbola et al.,2013). In June 2012, the Pakistani Taliban commander, Hafiz Gul Bahadur, banned polio vaccination days before 100,000 children were meant to receive OPV (Walsh, 2012). The commander feared that the Central Intelligence Agency (CIA) was using polio campaigns as a cover for espionage, just as they used Pakistani doctor Shakil Afridi to assist in tracking Osama Bin Laden (Rauhala, 2011; Walsh, 2012). Bahadur stated that the Taliban would interfere with vaccination campaigns until drone attacks stopped. Resistance to public health efforts has increased in Pakistan due to the backlash that resulted from the CIA exploiting Afridi, creating a setback for public health (Burke, 2012; Rauhala, 2011; Walsh, 2012). Past operations of the CIA have caused the belief that health volunteers are government agents, raising the risk of violence against them. Since July 2012, WHO has reported that 18 people have been killed and seven others injured during attacks in Pakistan, including vaccination volunteers and police officers.

In May 2013, two additional polio vaccination staff were shot and killed in north-west Pakistan leading to suspension of polio vaccination campaigns (Yusufzai, 2013). Additional vaccinators in Pakistan have been shot in 2014. The attention given to polio eradication in the international media has led terrorist groups to believe they can achieve their aims by interfering with polio eradication (Abimbola et al., 2013). 
The impact of attacks on polio workers in Pakistan has a shock value and an effective war strategy internationally.

In Nigeria in 2003, political and religious leaders of northern Nigerian states of Kano, Zamfara and Kaduna stopped vaccination campaigns by preventing parents from allowing their children to be vaccinated. These leaders believed that the vaccine was contaminated with anti-fertility agents such as estradiol, HIV and other pathogenic agents leading to a boycott and a halt of polio vaccination (Dreaper, 2013; Jegede, 2007). The background of this belief is easy to trace. During the 1980s, President Babangida embraced a policy to control the population by limiting the number of children a woman should have. The people of Nigeria responded to the policy by interpreting that the polio vaccination campaign was one method the government could use to reduce fertility (Jegede, 2007). While health policy is promulgated at the federal level, vaccination occurs at the primary level, under the jurisdiction of each state. Until 1999, the northern provinces dominated the Nigerian presidency. Since then, power shifted to the south, exacerbating many historical tensions between the north and south. This may explain why the northern states boycotted the polio campaign under the slogan to stop western influence (Callaway, 2013; Dreaper, 2013; Jegede, 2007). While the rumour that the polio vaccine contained harmful substances was unfounded, northern Nigerians - lack of trust in the federal government continues (Jegede, 2007).

The failure of polio eradication in Nigeria is not limited to its government. The Islamist Boko Haram movement of northern Nigeria became prominent in 2011 with post-election violence, political disaffection and lack of trust in the national government. In the ideology of mistrust in the government, militants and co-conspirators eager to attract attention from both in Nigeria and from other parts of the world can readily generate an offensive against polio vaccination workers (Abimbola et al., 2013). The meaning of Boko Haram, in simplicity, is 'book is forbidden'; books for Boko Haram members are the symbol of education (Abimbola et al., 2013). In north-eastern Nigeria, where Boko Haram has its deepest roots, some Muslims believe in prophetic medicine rather than spirits (Anonymous, 2012). Boko Haram's deceased founder, Mohammed Yusuf, objected to the concepts of secular modern medicine, such as regarding polio (Anonymous, 2012). For Yusuf, modern vaccines are no better than prophetic medicine. Combined with propaganda stating that the West is trying to reduce the population of Muslim communities via vaccination, these beliefs underscore Boko Haram's justification in attacking polio vaccination workers.

The current political climate of violence within the three remaining endemic countries is not conducive to global coordination as it was during the smallpox eradication programme. During the Cold War period, both superpowers the USA and Russia supported that programme (Arita, Nakane, \& Fenner, 2006). National vaccination campaigns continued successfully even during the long-standing wars between the north and south of Nigeria, India and Pakistan, and Ethiopia and Somalia (Arita et al., 2006; Jegede, 2007). In contrast, the polio eradication programme started at the end of the Cold War when many countries were realigning alliances and assuming more political independence (Arita et al., 2006). In geopolitical terms, there has also been a major increase in violent political conflicts within the Muslim world, with non-state actors such as the Taliban not hesitating to engage in terrorism as a political tool. In these regional power conflicts, actors easily brand public health initiatives such as vaccinations as ploys used by the 'enemy'. This resistance is exemplified by strong group identity, reliance on group cohesion 
and distrust of 'authority by/from others - felt by the disadvantaged minority (Heek, 1954). For example, vaccine refusals in Nigeria are found among marginalised communities who distrust government leaders, thus leading to suspicion in vaccination programmes (Jegede, 2007). Due to the ruse of the CIA's actions in Pakistan, there is an increase in the suspicion of western involvement in vaccination campaigns (Rauhala, 2011).

\section{Policy window}

The processes of public policy-making are setting the agenda, specification of an alternative from which a choice is made, making an authoritative choice among those specified alternatives and implementation of decisions (Kingdon, 1997). The purpose of setting the agenda is to narrow the range of issues that are focused on governmental agenda subjects, decisions and alternatives (Kingdon, 1997). Since the GPEI launched, the initiative continues to revise and update its agenda based on this agenda-setting process. In 2013, GPEI further revised its agenda when the WHA noted that ending polio was an emergency for global public health. The new endgame plan addresses what is needed to completely eradicate polio by 2018 by capitalising on the knowledge gained from the remaining endemic and re-established transmission nations (WHO, 2013). Subsequently, in May 2014, the Director General of WHO has declared the recent international spread of wild strains of polio a 'public health emergency of international concern' (PHEIC) and has issued temporary recommendations under IHR 2005 to reduce the global spread and importation of the wild strain of polio (CDC, 2014a). These recommendations specifically address remaining factors and barriers, using a 'top-down' authority approach.

As problems at the local level are identified, the political stream is where those list of problems are resolved, thus formulating the local and the global agendas (Kingdon, 1997). All need to expand that concept and realise that there are political streams in different arenas and at several levels that compete. Hence, the 'visible cluster' of policy actors includes stakeholders, such as WHO, GPEI, Rotary International, the CDC, the United Nations Children's Fund and Bill \& Melinda Gates Foundation, but should also include the Taliban, Boko Haram and the continued support of the Imams of Nigeria. With a current window opened by the PHEIC to make a list of alternatives, a new public policy can be selected by policy-makers to resolve the deadlock in polio eradication by focusing on two key factors: social and political (Kingdon, 1997).

\section{Options}

WHO and western health agencies apply vaccination by means of persuasion of the public rather than force. Much of the success of smallpox eradication was based on the technical promise of containment in an antiauthoritarian political climate (Greenough, 1995). Nevertheless, organised resistance provoked aggressive responses from vaccinators (Bhattacharya, 2010; Greenough, 1995). Opposition to vaccination was regarded as 'dangerous - to communities in areas that had been treated and was viewed as justification for the use of force. Mandated vaccination plans were implemented with the assistance of national and local administrative support including police and paramilitary units (Greenough, 1995). Mandating vaccination programmes and the resulting opposition take various forms and levels of intensity across the globe (Bhattacharya, 2010). Medical practice under martial control is, in principle, dysfunctional and unethical (Levy \& Sidel, 2008). Thus, the use of force can only be a short-term 
mandate and must clearly benefit the public at large. In the three remaining endemic countries, however, it is the political violence around other policy issues with the resulting breakdown of law enforcement that will make mandating the polio endgame a no-win strategy.

Alternatives to force are the benefits of respecting individual choice and securing individual/communal buy-in. To increase vaccination, the public must realise the severity of polio as a threat. Education for behavioural change has potential as a critical mediator in political, economic and social determinants of health (Aday, 2005). One assumes an educated person or community will take an action-based approach on four constructs representing perceived threats and net benefits: perceived susceptibility, perceived severity, perceived benefits and perceived barriers. Understanding these perceptions, a person will take a cue to action assuming that the individual understands his or her own self-efficacy (Glanz, Rimer, \& Lewis, 2002). One of the best ways to reduce health disparities and income inequalities while improving health of a country is to focus on policies that optimise adaptive behaviours. Therefore, if parents realise the severity of polio, vaccination rates would increase leading to a substantive increase in herd immunity. However, in the three endemic nations, implementing such educational strategies will be a challenge. The direct economic reasons for vaccination are not so transparent. Respecting individual freedoms and choice is an admirable goal, but building trust and knowledge through engaging communities and understanding their concerns as well can be a slow process. Moreover, individual freedom of choice regarding health may not fit with the cultural framework of the populations that are targeted.

Politically, it may be more effective to gain support of those who are vulnerable to fundamentalist propaganda by using moderate leaders. Hence, religious and tribal leaders should continue to be asked to support polio eradication programmes, although each country will have its own specific issues. For example, the Imam of the Ka'aba (Nigeria) and other influential leaders should be asked to discuss the quality of life of children affected by polio, especially in light of having a preventive solution available such as 'Allah made it possible for humans to use their science and invent a vaccine; or Allah gave us the vaccine, so now let's use it' (Warraich, 2009). While the Taliban is now allowing vaccination again in Afghanistan, this may only be temporary until there is another 'misunderstanding'. This is especially important in Pakistan, where polio campaigns have been suspended, as major mistrust in polio vaccinators continues.

Taylor (2009) argues that when a programme prefers the political safety of educational problems rather than the wider problems of governance and the distribution of wealth and well-being, such as the polio eradication programme, the global consequences can be that it will find itself blocked in the last mile of a long race.

Hence, we see that the local political situation surrounding polio eradication is the most serious barrier to be dealt with in eradicating polio. If the political factors are not remedied, polio eradication will absolutely be delayed. With the intensification of the GPEI launch of their 'endgame' strategy, and applying the PHEIC edict, 'attention needs to be paid now to strengthen engagement with local communities - (Ghinai, Willott, Dadari, \& Larson, 2013). Ghinai et al. (2013) argues that, if attention is not paid to the local communities and deterrents, another crisis such as the boycott in Nigeria in 2003 may occur, undermining the progress of the GPEI. Therefore, the involvement of local policy actors in a consensus frame must be established and carefully maintained in order for the policy window to remain open. Beyond using the force of a PHEIC edict on polio, it will be essential to understand the networks of these actors and who in 
the networks can create the leverage needed to persuade the belligerent factions to 'isolate the medical act from the political act'.

\section{Conclusion}

The efforts and resources allocated to polio eradication thus far have indeed been substantial; however, the notion that polio is almost eradicated is not sufficient. Polio eradication should be considered as an 'all or none' situation. All policy options will require more funding in certain aspects, but funding has never been the central issue. The most important issues to focus on now are the local social and political factors. It is essential that the polio eradication campaigns are negotiated away from the political strife in the three regions discussed. There is an urgent need to create a frame of reference that all parties can agree on. We believe that the temporary character of the steps that can be taken as part of the new IHR does not create such a reference for the long haul.

Polio vaccination is part of a larger set of children's health issues that should be addressed worldwide. In that sense, the Convention on the Rights of the Child (1989) provides a first step of such a frame of reference. Building on that treaty, we suggest considering a type of 'Geneva Convention' for children's health which regulates how health care delivery and vaccinations can be implemented if and when there is a state of violent political conflict, such as violence towards vaccination workers. This would potentially and eventually benefit all parties and stakeholders involved. GPEI could serve as the catalyst that determines the parameters of such a convention. Without enhanced negotiation and diplomacy, and consideration of a more targeted approach to public health in areas of local conflicts, the progress to polio eradication will probably be delayed far beyond 2018.

\section{Disclosure statement}

No potential conflict of interest was reported by the authors.

\section{References}

- 1. Abimbola, S., Malik, A. U., \& Mansoor, G. F. (2013). The final push for polio eradication: Addressing the challenge of violence in Afghanistan, Pakistan, and Nigeria. PLOS Medicine, 10(10), e1001529. doi:10.1371/journal.pmed.1001529 [CrossRef],[PubMed], [Web of Science $\left.{ }^{\circledR}\right]$

- 2. Aday, L. A. (Ed.). (2005). Reinventing public health: Policies and practices for a healthy nation (1st ed.). San Francisco, CA: Jossey-Bass.

- 3. Anonymous. (2012). The popular discourses of salafi radicalism and salafi counter-radicalism in Nigeria: A case study of Boko Haram. Journal of Religion of Africa, 42(2), 118-144.

doi:10.1163/15700666-12341224 [CrossRef], [Web of Science ${ }^{\circledR}$ ]

- 4. Arita, I., Nakane, M., \& Fenner, F. (2006). Is polio eradication realistic? Science, 312, 852-854. doi:10.1126/science.1124959[CrossRef], [PubMed], [Web of Science ${ }^{\circledR}$ ]

- 5. Babakarkhail, Z., \& Nelson, D. (2013, May 13). Taliban renounces war on anti-polio workers. The Telegraph. Retrieved

fromhttp://www.telegraph.co.uk/news/worldnews/asia/afghanistan/10053981/Taliban-renounces-war-onanti-polio-workers.html

- 6. Bhattacharya, S. (2010). Reflections on the eradication of smallpox. Lancet, 375, 1602-1603. doi:10.1016/S0140-6736(10)60692-7 [CrossRef], [PubMed], [Web of Science $®$ ] 
- 7. Burke, J. (2012, December 18). Polio vaccination workers shot dead in Pakistan. The Guardian. Retrieved fromhttp://www.theguardian.com/world/2012/dec/18/polio-vaccination-workers-shot-pakistan

- 8. Cakouros, B. E. (2012). The impact of the vaccine supply chain on the socioeconomic status of regions in Niger. Unpublished manuscript.

- 9. Callaway, E. (2013). Public health: Polio's moving target. Nature, 496, 290-292. doi:10.1038/496290a [CrossRef], [PubMed],[Web of Science ${ }^{\circledR}$ ]

- 10. CCP. (2013). College of physicians of Philadelphia: History of vaccines. Retrieved from http://www.historyofvaccines.org

- 11. CDC. (2013a). Progress toward poliomyelitis eradication-Afghanistan, January 2012-September 2013. Morbidity and Mortality Weekly Report (MMWR), 62, 928-933. [Web of Science $®$ ]

- 12. CDC. (2013b). Progress towards poliomyelitis eradication-Nigeria, January 2012-September 2013. Morbidity and Mortality Weekly Report (MMWR), 62, 1009-1013. [Web of Science $®$ ]

- 13. CDC. (2014a). Progress towards polio eradication-worldwide, 2013-2014. Morbidity and Mortality Weekly Report (MMWR), 63, 468-472. [PubMed], [Web of Science ${ }^{\circledR}$ ]

- 14. CDC. (2014b). Updates on CDC's polio eradication efforts. Retrieved from http://www.cdc.gov/polio/updates/

- 15. Dreaper, J. (2013, January 14). The barriers to Nigeria's battle to contain polio. BBC News Health. Retrieved fromhttp://www.bbc.com/news/health-20819972

- 16. Gautam, K. (2005). A history of global polio eradication. UNICEF. Retrieved fromhttp://www.unicef.org/immunization/files/the_history_of_polio.pdf

- 17. Ghinai, I., Willott, C., Dadari, I., \& Larson, H. J. (2013). Listening to the rumours: What the northern Nigeria polio vaccine boycott can tell us ten years on. Global Public Health, 8, 1138-1150. doi:10.1080/17441692.2013.859720 [Taylor \& Francis Online], [PubMed], [Web of Science ${ }^{\circledR}$ ]

- 18. Glanz, K., Rimer, B. K., \& Lewis, F. M. (2002). Health behavior and health education. Theory, research, and practice. San Francisco, CA: Wiley \& Sons.

- 19. GPEI. (2014). Global polio eradication initiative. Retrieved from http://www.polioeradication.org/

- 20. Greenough, P. (1995). Intimidation, coercion and resistance in the final stages of the south Asian smallpox eradication campaign. Social Science \& Medicine, 41, 633-645. doi:10.1016/02779536(95)00035-6 [CrossRef], [PubMed], [Web of Science ®], [CSA]

- 21. Heek, V. F. (1954). Het geboorte-niveau der Nederlandse rooms-katholieken. Een demografischsociologische studie van een geemancipeerde minderheidsgroep [The birth level of Dutch Roman Catholics. A demographic-sociological study of an emancipated minority group]. Leiden: Stenfert Kroese. Retrieved from http://www.dbnl.org/tekst/heek001gebo01_01/

- 22. Jegede, A. S. (2007). What led to the Nigerian boycott of the polio vaccination campaign? PLoS Medicine, 4(3), e73. doi:10.1371/journal.pmed.0040073.sd001 [CrossRef], [PubMed], [Web of Science ®]

- 23. Kingdon, J. W. (1997). Agendas, alternatives, and public policies (2nd ed.). New York, NY: HarperCollins.

- 24. Lahariya, C. (2007). Global eradication of polio: The case for "finishing the job". Bulletin of the World Health Organization, 85, 487-492. doi:10.2471/BLT.06.037457 [CrossRef], [PubMed], [Web of Science (B]

- 25. Levy, B., \& Sidel, V. (Eds.). (2008). War and public health (2nd ed.). Oxford: Oxford University Press. [CrossRef] 
- 26. Marmot, M. (2014). Review of social determinants and health divide in the WHO European region: Executive summary. Copenhagen: UCL Institute of Health Equity, WHO Regional Office for Europe.

- 27. Modlin, J. F. (2010). The bumpy road to polio eradication. New England Journal of Medicine, 362, 2346-2349. doi:10.1056/NEJMp1005405 [CrossRef], [PubMed], [Web of Science ${ }^{\circledR}$ ]

- 28. Nathanson, N., \& Kew, O. M. (2010). From emergence to eradication: The epidemiology of poliomyelitis deconstructed.American Journal of Epidemiology, 172, 1213-1229. doi:10.1093/aje/kwq320 [CrossRef], [PubMed], [Web of Science ${ }^{\circledR}$ ]

- 29. Osazuwa-Peters, N. (2011). Determinants of health disparities: The perennial struggle against polio in nigeria. International Journal of Preventive Medicine, 2(3), 117-121.

- 30. Popalzai, M. (2012). Afghan Taliban support polio vaccination campaign. Retrieved fromhttp://www.cnn.com/2012/01/17/world/asia/taliban-polio-vaccinations/index.html

- 31. Rauhala, E. (2011, July 18). Why the CIA's vaccine ruse is a setback for global health. Time. Retrieved fromhttp://world.time.com/2011/07/18/why-the-cias-vaccine-ruse-is-a-setback-for-global-health/

- 32. Taylor, S. (2009). Political epidemiology: Strengthening socio-political analysis for mass immunisation - Lessons from the smallpox and polio eradication programmes. Global Public Health, 4, 546-560. doi:10.1080/17441690701727850 [Taylor \& Francis Online], [PubMed], [Web of Science ${ }^{\circledR}$ ]

- 33. Toole, M., Simmonds, S., Coghlan, B., \& Mojadidi, N. (2009). Evaluation of global polio eradication initiative. (Independent evaluation no. 1). Global Polio Eradication Initiative. Retrieved fromhttp://www.polioeradication.org/content/general/Polio_Evaluation_AFG.pdf

- 34. Trofimov, Y. (2010, January 15). Risky ally in war on polio: The Taliban. The Wall Street Journal. Retrieved fromhttp://online.wsj.com/articles/SB126298998237022117

- 35. UNICEF. (2012). Empowering women on the frontlines. Retrieved from http://polioinfo.org/index.php/communication-in-action/afghanistan/stories-from-the-field/207empowering-women-on-the-frontlines

- 36. Walsh, D. (2012, June 18). Taliban blocks vaccinations in Pakistan. New York Times. Retrieved fromhttp://www.nytimes.com/2012/06/19/world/asia/taliban-block-vaccinations-in-pakistan.html

- 37. Warraich, H. J. (2009). Religious opposition to polio vaccination. Emerging Infectious Diseases, 15, 978. doi:10.3201/eid1506.090087 [CrossRef], [PubMed], [Web of Science ®]

- 38. WHO. (2010). Global polio eradication strategic national plan 2010-2012. (Strategic plan no. 2). Geneva: Author.

- 39. WHO. (2012). Poliomyelitis: Intensification of the global eradication initiative. Paper presented at Sixty-Fifth World Health Assembly, World Health Organization, Geneva, Switzerland.

- 40. WHO. (2013). Polio eradication \& endgame strategic plan 2013-2018. (WHA Version). Geneva: Global Polio Eradication Initiative.

- 41. Yusufzai, M. (2013, May 28). WHO suspends Pakistan operations after polio workers shot dead. NBC. Retrieved fromhttp://worldnews.nbcnews.com/_news/2013/05/28/18558500-who-suspendspakistan-operations-after-polio-workers-shot-dead 